\title{
Baseline Staging of Newly Diagnosed Breast Cancer - Kuwait Cancer Control Center Experience
}

\author{
Sadeq Abuzallouf Mohammad Motawy Ziad Thotathil \\ Department of Radiation Oncology, Kuwait Cancer Control Center, Kuwait
}

\section{Key Words}

Breast cancer $\cdot$ Metastases $\cdot$ Staging procedures

\begin{abstract}
Objective: To determine the value of staging investigations in detecting metastases in newly diagnosed asymptomatic patients with breast cancer. Materials and Methods: A retrospective review of patients' files with newly diagnosed breast cancer in the period from 1993 to 1998 was performed. Due to inadequate information, thirty-eight files were excluded leaving 785 files for analysis. Results: Of the total 785 patients, we found distant metastases at the time of primary diagnosis in 36 (4.6\%) patients, bone metastases in 29 (3.7\%) patients, pulmonary metastases in $6(0.8 \%)$ patients and liver metastases in $5(0.6 \%)$ patients. Overall, $0.7 \%$ of patients with clinical stage I and II disease had metastases compared with $16.2 \%$ of patients with clinical stage III disease (statistically significant $\mathrm{p}=0.0001$ ). Conclusion: The results confirm the low yield of routine bone scans, liver ultrasound and chest X-ray among patients with asymptomatic early-stage breast cancer. These tests are therefore not recommended for such patients, although intensive investigations are appropriate for more advanced tumors.
\end{abstract}

Copyright $\odot 2007$ S. Karger AG, Basel

\section{KARGER}

Fax +4161306 1234

E-Mail karger@karger.ch

www.karger.com
(C) 2007 S. Karger AG, Basel

1011-7571/07/0161-0022\$23.50/0

Accessible online at:

www.karger.com/mpp

\section{Introduction}

Many patients have extensive staging investigations to complete their metastatic workup following a diagnosis of breast cancer $[1,2]$. The goal of these tests is to identify those patients with incurable disease so that a more realistic prognosis can be given and their treatment tailored accordingly. Bone scan (BS), liver ultrasound (LUS) and chest X-ray (CXR) are still commonly used to detect subclinical metastatic disease [3]. The usefulness of these tests is questionable [4-6], especially when one considers both their sensitivities and specificities.

The aim of this study was to determine the frequency and distribution pattern of metastases at the time of primary surgery, and to identify a group of breast cancer patients in whom imaging studies for staging can be omitted.

\section{Materials and Methods}

From January 1993 to 1998, 823 consecutive patients with primary breast cancer had surgery and subsequent therapy at Kuwait Cancer Control Center. Thirty-eight files were excluded from the analysis because of inadequate information, leaving 785 files for further analysis. All patients were clinically staged by physical 
Table 1. Distribution pattern of metastases to sites at risk based on TNM staging

\begin{tabular}{lrllllll}
\hline Stage & Bone & Lung & Liver & $\begin{array}{l}\text { Bone/ } \\
\text { liver }\end{array}$ & $\begin{array}{l}\text { Lung/ } \\
\text { liver }\end{array}$ & $\begin{array}{l}\text { Bone/ } \\
\text { lung }\end{array}$ & Total \\
\hline IIA(T1N1) & - & - & 1 & - & - & - & 1 \\
IIB(T2N1) & 2 & - & - & - & - & - & 2 \\
IIB(T3N0) & 1 & - & - & - & - & - & 1 \\
IIIA(T3N1) & 5 & 1 & - & 1 & - & - & 7 \\
IIIA(T2N2) & 1 & - & - & - & - & - & 1 \\
IIIA(T3N2) & 1 & - & - & - & - & - & 1 \\
IIIB(T4N0) & 1 & - & - & - & - & - & 1 \\
IIIB(T4N1) & 4 & - & 1 & - & - & - & 5 \\
IIIB(T4N2) & 11 & 3 & - & 1 & 1 & 1 & 17 \\
\hline Total & 26 & 4 & 2 & 2 & 1 & 1 & 36 \\
\hline
\end{tabular}

examination to determine their $\mathrm{T}$ and $\mathrm{N}$ stages. Routine investigations with CXR, LUS and BS were then carried out to detect subclinical metastases. The detection rate of metastases was correlated with clinical staging. Staging was modified according to the American Joint Committee on Cancer classification system 2002 [7]. A $\chi^{2}$ test was used to determine wether metastases were significantly different between early and advanced stages.

\section{Results}

In general, $52 \%$ of the patients were Kuwaiti compared to $48 \%$ Non-Kuwaiti. The median age of the patients was 45 years. Premenopausal patients constituted $63 \%$ of the total cases. Metastases were found with routine imaging studies in $36 / 785$ (4.6\%) patients at the time of primary surgery. About $28 \%$ of the cases were premenopausal. Metastases were more frequent in bone $(26 / 785$ patients, $3.3 \%)$, followed by lung ( $0.5 \%)$ and liver $(0.3 \%)$. Synchronous metastases were found in bone and liver in 2 cases, lung and liver in 1 case and bone and lung metastases in 1 case (table 1). The detection rate of subclinical metastases was low (0.7\%) in early-stage breast cancer compared to locally advanced (16.2\%) stages. This was statistically significant $(\mathrm{p}=0.0001)$. Bone metastasis rates were $0 \%$ for patients with stage I and IIA disease, $1.4 \%$ for patients with stage IIB, 9.2\% for patients with stage IIIA and $16.2 \%$ for patients with stage IIIB. Liver metastasis rates were 0 , $0.4,0,1.2$, and $2.7 \%$ for stage I, IIA, IIB, IIIA and IIIB disease, respectively. As for lung metastasis, it was found in only $3 \%$ of patients with stage III disease and none in stage I and II disease (table 2).
Table 2. Frequency and distribution pattern of metastases according to clinical staging

\begin{tabular}{llllllc}
\hline \multirow{2}{*}{ Stage } & \multicolumn{2}{c}{ Metastasis } & & \multicolumn{2}{c}{ Total number of } \\
& bone & liver & lung & & metastases & patients \\
\hline I & 0 & 0 & 0 & 0 & 134 \\
IIA & 0 & 1 & 0 & 1 & 234 \\
IIB & 3 & 0 & 0 & 3 & 219 \\
IIIA & 8 & 1 & 1 & 9 & 87 \\
IIIB & 18 & 3 & 5 & 23 & 111 \\
\hline
\end{tabular}

\section{Discussion}

It has been shown that the prevalence of detectable metastatic disease in newly diagnosed breast cancer patients is exceedingly low and increases from stage I to stage III [8-9]. Ravaioli et al. [8] reviewed data about staging procedures on 1,218 breast cancer patients. An overall prevalence of $1.46 \%$ was reported when results of BS, LUS and CXR were analyzed together in patients with low-risk tumor characteristics (pT1-T3 and a number of positive nodes $\leq 3$ ). On the other hand, in patients belonging to the high-risk group (pT4 or a number of positive nodes $>3$ or $\mathrm{pN} 2$ ), the prevalence was $10.68 \%$.

This study reports a relatively low detection rate $(0.7 \%)$ of subclinical metastases in early stages (stage I and II) of breast cancer as only 4 patients were found to have metastases with no clinical or biochemical abnormalities. The significance of such low value may be lowered further since there is no clinical evidence of improved prognosis with early treatment of asymptomatic metastases compared to treatment after the onset of symptoms.

In a systematic review, Myers et al. [9] reported positive BS at baseline from 0.9 to $40 \%$ with the lowest prevalence observed in stage I and the highest in stage III patients. In our study, no patient with stage I or IIA disease was found to have distant bone metastases compared to $13.1 \%$ with stage III disease.

Studies evaluating the role of LUS in detecting liver metastases showed an even lower prevalence than that observed in the studies of BS: $0 \%$ for stage I, $0.4 \%$ for stage II and $2 \%$ for stage III [9]. In this study, liver metastasis was found in 5 patients $(0.6 \%)$. There was no liver metastasis in patients with stage I breast cancer. In stage II and III disease, we detected liver involvement in 0.2 and $2 \%$, respectively.

In a large study $(n=1,493)$ designed to identify patients with early breast cancer who were upstaged to stage 
IV by CXR, Chen et al. [10] found pulmonary metastases in less than $0.1 \%$ of asymptomatic patients. In this study, pulmonary metastases were present in only 6 of 785 patients $(0.8 \%)$. All of them had stage III disease. Although many anesthetists traditionally require CXR before general anesthesia, there is no strong medical indication for routine preoperative CXR in asymptomatic, otherwise healthy breast cancer patients [11]. Furthermore, CXR has never been shown to improve outcome in the care of patients with clinical stage I or II breast cancer [10]. Our data support the view that CXR may be eliminated in the routine staging for asymptomatic patients with stage I or II breast cancer.

\section{Conclusion}

Our results confirm the low yield of metastases at initial presentation of operable early breast cancer (clinical stage I and II) and the relatively low yield of routine BS, LUS and CXR in asymptomatic patients. Therefore, such investigations should not be routinely done unless the results of initial clinical assessment or blood work reveal abnormalities. However, in locally advanced (clinical stage III) breast cancer, the incidence of metastases is much higher (16.2\%), and more extensive investigations with BS, LUS and CXR are warranted.

\section{References}

-1 Khansur TR, Haick A, Patel B, Balducci L, Vance R, Thigpen T: Evaluation of bone scan as a screening work-up in primary and localregional recurrence or breast cancer. Am J Clin Oncol 1987;10:167-170.

-2 Nomura Y, Kondo H, Yamagata J, Kanda K, Takenaka K, Maeda T, Shiokawa H: Evaluation of liver and bone scanning in patients with early breast cancer, based on results obtained from more advanced cancer patients. Eur J Cancer 1978;14:1129-1136.

$\checkmark 3$ Baker RR: Preoperative assessment of the patient with breast cancer. Surg Clin North Am 1984;64:1039-1050.

4 Berman CG, Clark RA: Diagnostic imaging in cancer. Prim Care 1992;19:677-713.
5 Kinne DW: Staging and follow-up of breast cancer patients. Cancer 1991;67:1196-1198.

$\checkmark 6$ Lee YT: Bone scanning in patients with early stage breast cancer: should it be a routine staging procedure? Cancer 1981;47:486495.

7 Woodward WA, Strom EA, Tucker SL, McNeese MD, Perkins GH, Schechter NR, Singletary SE, Theriault RL, Hortobagyi GN, Hunt KK, Buchholz TA: Changes in the 2003 American Joint Committee on Cancer staging for breast cancer dramatically affect stage-specific survival. J Clin Oncol 2003;21: 3244-3248.

8 Ravaioli A, Pasini G, Polselli A, Papi M, Tassinari D, Arcangeli V, Milandri C, Amadori D, Bravi M, Rossi D, Fattori PP, Pasquini E, Panzini I: Staging of breast cancer: new recommended standard procedure. Br Cancer Res Treat 2002;72:53-60.
-9 Myers RE, Johnston M, Pritchard K, Levine $\mathrm{M}$, Oliver T: Baseline staging tests in primary breast cancer: a practice guideline. Can Med Assoc J 2001;164:1439-1444.

10 Chen EA, Carlson GA, Coughlin BF, Reed WP Jr, Grab JL, Frank JL: Routine chest roentgenography is unnecessary in the workup of stage I and II breast cancer. J Clin Oncol 2000;18:3503-3506.

$\checkmark 11$ Tape TG, Mushlin AI: How useful are routine chest X-rays of preoperative patients at risk for postoperative chest disease? J Gen Intern Med 1988;3:15-20. 